\title{
Design of single phase inverter for photovoltaic application controlled with sinusoidal pulse width modulation
}

\author{
Ibrahim Alhamrouni ${ }^{1}$, N. Zainuddin ${ }^{2}$, Mohamed Salem ${ }^{3}$, Nadia H. A. Rahman ${ }^{4}$, Lili Awalin ${ }^{5}$ \\ 1,2,4,5Electrical Engineering Section, University Kuala Lumpur (UniKL BMI), Malaysia \\ ${ }^{3}$ School of Electrical and Electronic Engineering, Universiti Sains Malaysia, Malaysia
}

\begin{tabular}{l}
\hline Article Info \\
\hline Article history: \\
Received Oct 1, 2018 \\
Revised Dec 10, 2018 \\
Accepted Jan 25, 2019 \\
\hline
\end{tabular}

\section{Keywords:}

Bipolar switching scheme

Photovoltaic

Renewable energy

Single phase inverter

Sinusoidal pulse width

modulation

Unipolar switching scheme

\begin{abstract}
The application of fossil fuels like coal, oil and gas gives enormous environmental impact and hazardous effects to the earth. Hence, renewable energy has become the most tremendously friendly method to generate electricity without pollution and emissions. Inverter is a power electronics device which is used to convert Direct Current (DC) into Alternating Current (AC). The conventional inverter no longer fulfills the requirement of reducing harmonic distortions, plus it causes global warming and greenhouse effect. For increasing the efficiency and reliability of the system, the PV inverter becomes a vital part in the conversion of $\mathrm{DC}$ to $\mathrm{AC}$ output. This research thus presents a single phase photovoltaic inverter controlled with sinusoidal pulse-width-modulation (SPWM) and low pass filter connection between the inverter and the utility grid to reduce the harmonics resulted due to intermittent nature of the renewable energy sources. Unipolar and Bipolar switching scheme are applied to control the magnitude and frequency of output voltage and result of both unipolar and bipolar are compared. The simulation of the proposed technique is executed by using Matlab/Simulink.
\end{abstract}

Copyright $(2019$ Institute of Advanced Engineering and Science. All rights reserved.

Corresponding Author:

Ibrahim Alhamrouni,

Electrical Engineering Section,

University Kuala Lumpur (UniKL BMI),

Gombak 53100, Malaysia.

Email: Ibrahim.mohamed@unikl.edu.my

\section{INTRODUCTION}

Nowadays, there has been a rapid growth in electrical energy usage which also results in increasing the production of renewable energy. Currently, there are various applications of energy sources but unfortunately, most of the sources of energy obtained from common fossil fuels that resulting in global emission and greenhouse effect [1-3]. Renewable energy is generated from replenished natural sources and can be transformed to electricity through the conversion technologies such as solar and wind turbine. However, this method is yet to be in the process of acquiring high market penetration level and technological advancement.

The use of different renewable energy as an energy source currently have developed involvement of distributed generation but the output power from these RE sources is unsteady [4]. Therefore, the most tremendous way to acquire the stability is by implementing the power electronics interface system such as a modern inverter system [5,6]. For increasing the efficiency and reliability of the utility grid, the smart inverter becomes a vital part of the distributed generation interface [7, 8]. Typically, the inverter often assigned for converting input of DC voltage to an output of $\mathrm{AC}$ voltage and function as an interface in the middle of the renewable energy and the utility grid $[9,10]$. However, the injected harmonic of the output current and effectiveness of the inverter are the vital issues [11]. To reduce the power quality interruption from the system, different types of inverter structure have been implemented [12, 13]. The IGBT is 
implemented in the conversion of DC to AC output [14, 15]. This work is organized in the following sections. In Section 2, the proposed system configuration is outlined. The simulation part is explained in Section 3. In addition, the analysis performance of the two switching schemes are compared in Section 4. A discussion on the obtained results have been presented in Section 5, while Section 6 is the conclusion of the current work.

\section{PROPOSED SYSTEM CONFIGURATION}

The basic block diagram of the proposed system is illustrated in Figure 1.

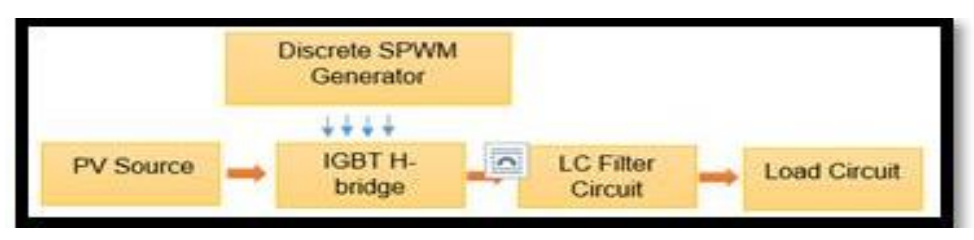

Figure 1. Block diagram of proposed model

\subsection{PV Source}

The main input power for the inverter is the power produced by the solar panel. The use of DC-DC converter is preferred to cater the problem of the fluctuation encountered to stabilize the voltage. The frequency used for this circuit is set to be $50 \mathrm{~Hz}$.

\subsection{IGBT Full H-Bridge Inverter}

The number of semiconductor used are based on the configuration of the inverter either half bridge or full bridge [16]. Due to the implementation of full bridge configuration, it contains of four IGBTs. The IGBT gate are generated by the means of SWPM pulses.

\subsection{SPWM Generator}

The SPWM generator will produce pulses for Sinusoidal Pulse Width Modulation switching scheme.

\subsection{Filter and Load Circuit}

The IGBTs will generate some harmonic component at the output hence, this filter circuit will filter the harmonic content. Resistor will be the load for this circuit.

\section{SINUSOIDAL PULSE WIDTH MODULATION}

SPWM is developed by comparing the sinusoidal waveform as modulation waveform with the triangular waveforms or (saw tooth waveform) as carrier waveform whose much higher frequency than the modulation wave. SPWM generator showing a better accomplishment with the achievement of better switching frequency, better resolution of SPWM waveforms and lesser harmonic distortion [17]. There are two types of SPWM switching which are unipolar switching and bipolar switching. For this research, both switching schemes will be implemented hence both result will be compared.

\subsection{Simulation}

To begin with, the proposed inverter for both schemes are simulated in Matlab/Simulink and the results for both schemes are observed. Simulation is executed with discrete power and fixed at 0.1 sec sample time. The simulation models of both SPWM unipolar and bipolar switching scheme are demonstrated in the Figures 2 and 3.

\subsection{Circuit Description}

The proposed design is constructed based on two different switching techniques as follows:

\subsubsection{Case 1: Unipolar Switching Scheme}

The unipolar modulation normally requires two sinusoidal modulating waves vm and -vm which are of same magnitude and frequency but $180^{\circ}$ out of phase. The two modulating wave are compared with a 
common triangular carrier wave Vcr generating two gating signals Vg1 and Vg3. For unipolar switching scheme, there are two legs whose G1 and G2 are on one leg while G3 and G4 are in another leg [18]. When the G1 turned on, the G2 is turned off and vice versa. The output voltage for unipolar switching can be either $-\mathrm{Vdc}$ during negative half cycle, $0 \mathrm{Vdc}$ or $+\mathrm{Vd}$ during positive half cycle.

\subsubsection{Case 2: Bipolar Switching Scheme}

Nevertheless, for bipolar switching inverter, the switches are organized diagonally. The upper and the lower switches in the same inverter leg work in a complementary manner with one switch turned on and other turned off. Thus we need to consider only two independent gating signals vg1 and vg3 which are generated by comparing sinusoidal modulating wave vm and triangular carrier wave vcr. It can be noticed that when S1S4 is switched on, the S2S3 is switched off and vice versa [19]. The process of bipolar method is the same as unipolar method, however only one sinusoidal signal is compared with triangular waveform without inversing it.

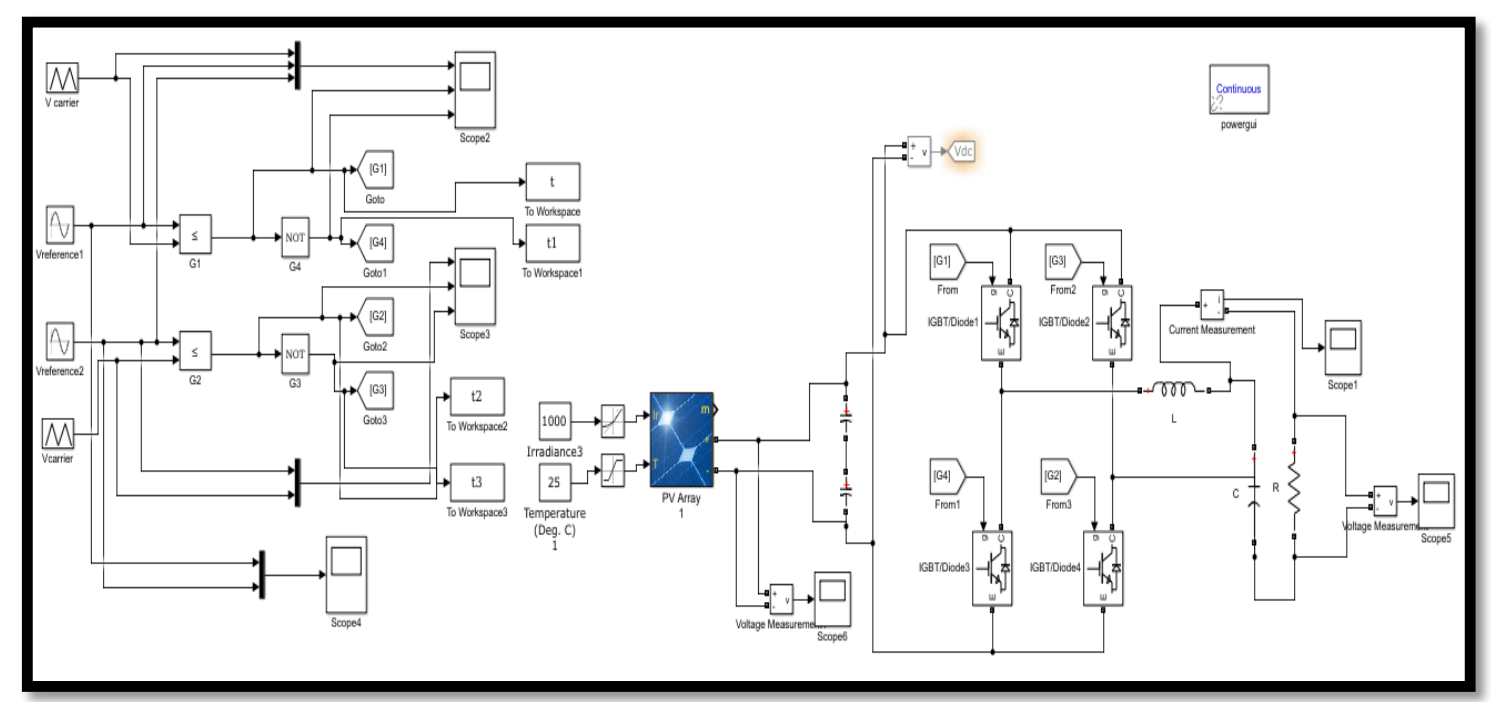

Figure 2. SPWM unipolar switching scheme

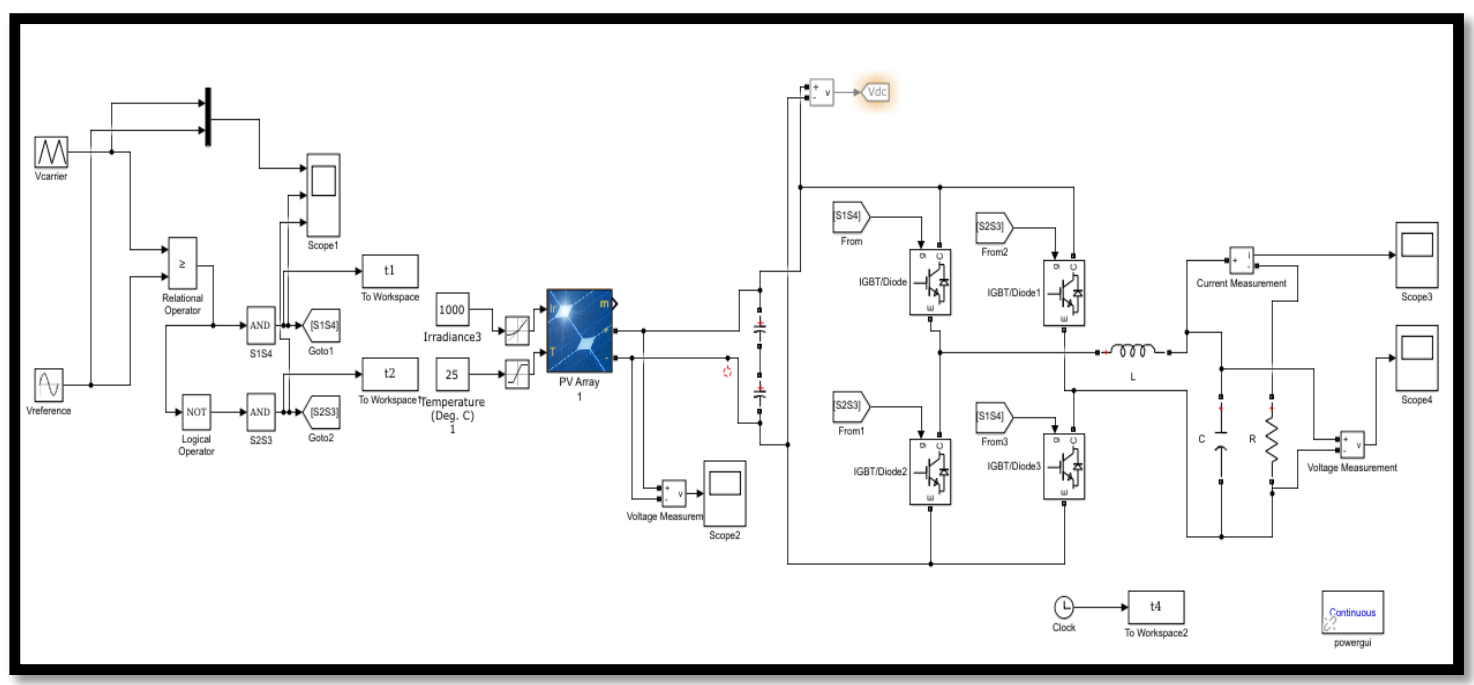

Figure 3. SPWM bipolar switching scheme

\section{RESULT AND ANALYSIS}

The proposed design is analysed from different aspects, according to the switching technique used. A detailed comparison between the two applied switching techniques is as follows: 


\subsection{Analysis of SPWM Output Waveform}

The SPWM output waveform has been obtained based on two different switching schemes, namely, unipolar and bibolar switching schemes.

\subsubsection{Case 1: Unipolar Switching Scheme}

Figure 4 exhibits SPWM Pulse Generator Circuit that use two sine wave signal (reference signal) has $180^{\circ}$ phase opposite to each other compared with triangular wave and produce switching pulses to the IGBT [20-22].

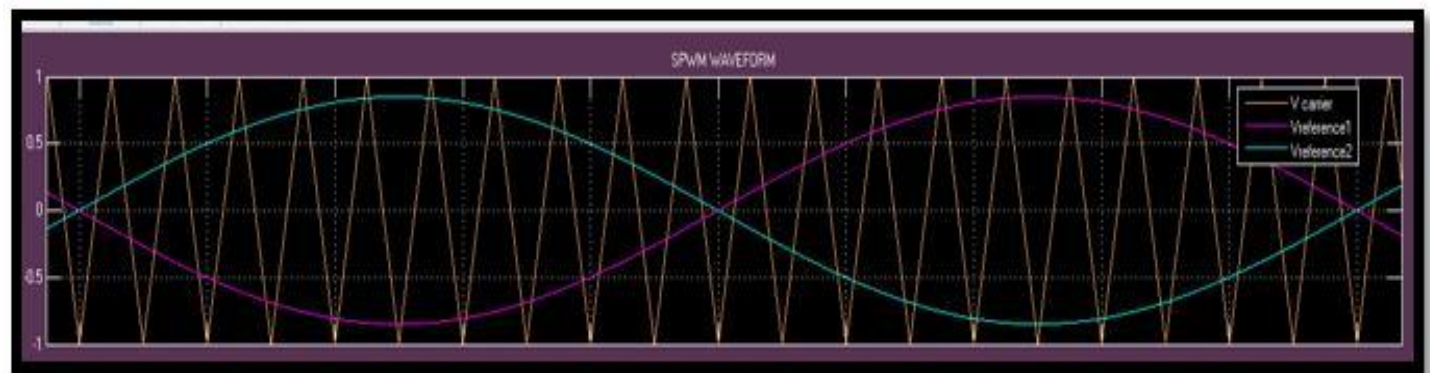

Figure 4. Output waveform of SPWM unipolar

The PWM pulse generator block generates the four PWM pulses as illustrated in Figures 5 and 6. Hence, these pulses are given to the gates of the IGBTs for turning on and off.

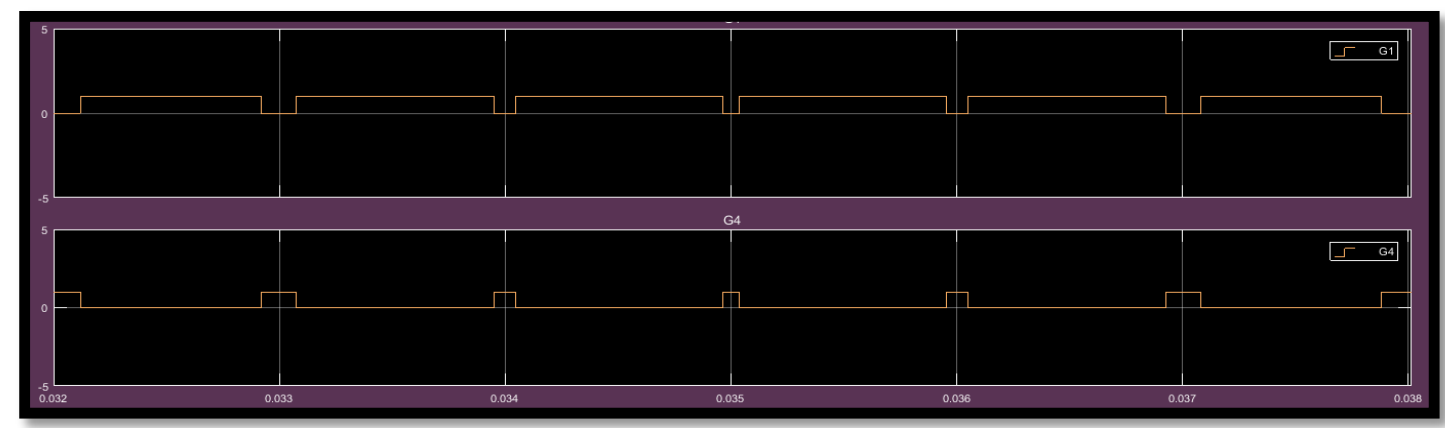

Figure 5. Pulse generated by IGBT G1 and G4

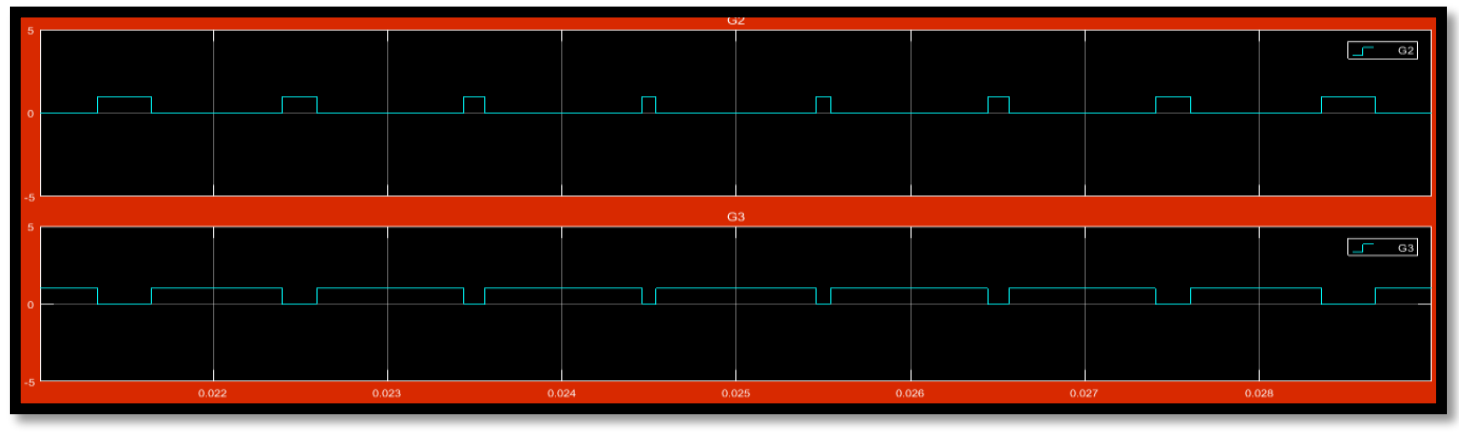

Figure 6. Pulse generated by IGBT G2 and G3

\subsubsection{Case 2: Bipolar Switching Scheme}

Figure 7 exhibits SPWM Pulse Generator Circuit generated by comparing one sinusoidal modulating wave vm and triangular carrier wave vcr to produce switching pulses to the IGBT. 


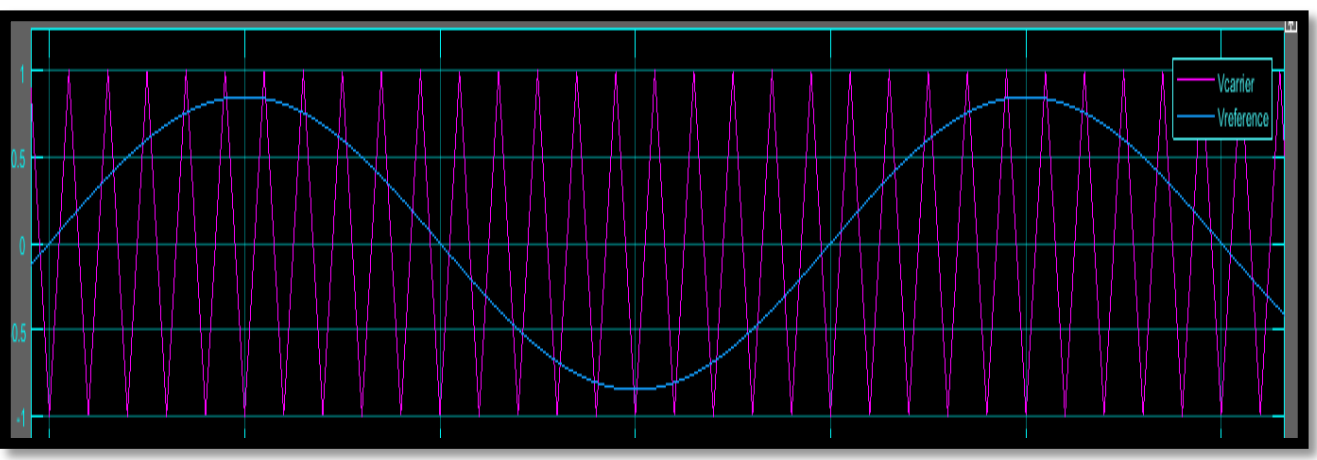

Figure 7. Output waveform of SPWM bipolar

The PWM pulse generator block generates the two PWM pulses S1S4 and S2S3 as illustrate in Figure 8. Hence, these pulses are given to the gates of the IGBTs for turning on and off.

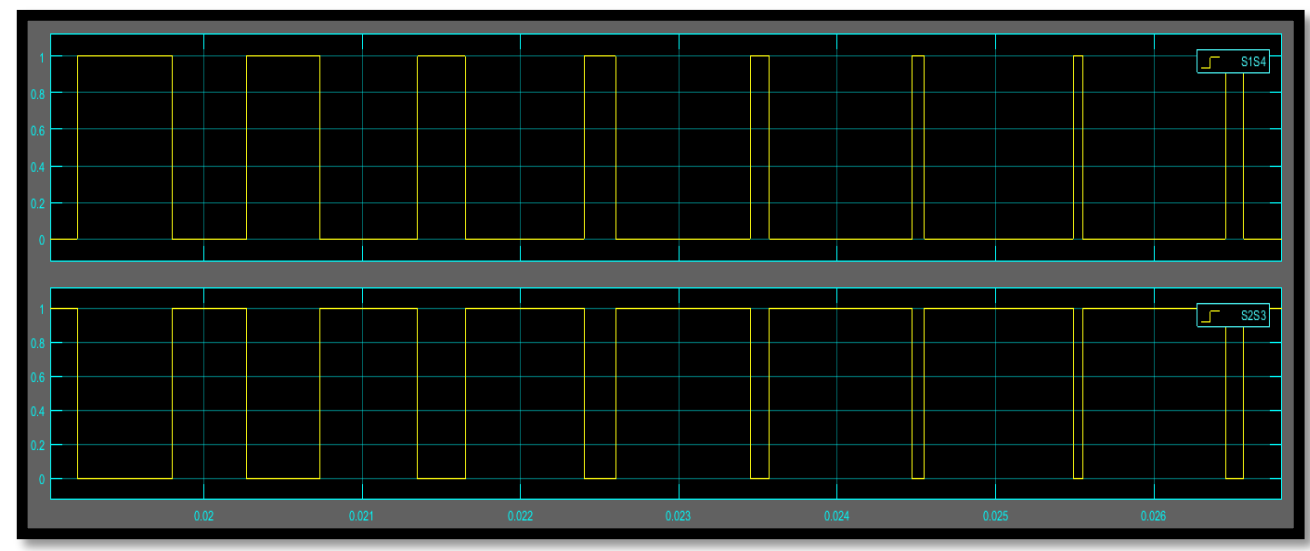

Figure 8. Pulse generated by S1S4 and S2S3

\subsection{Analysis of Output Voltage and Current}

The output current and voltage waveforms are analysed as follows:

\subsubsection{Case 1: Unipolar Switching Scheme}

The output rms initiate that the rms voltage and current for unipolar scheme are $237.6 \mathrm{~V}$ and $4.752 \mathrm{~A}$ respectively. The filtered AC output current and voltage produced by unipolar switching scheme acquired from simulation are demonstrate in Figure 9 and 10.

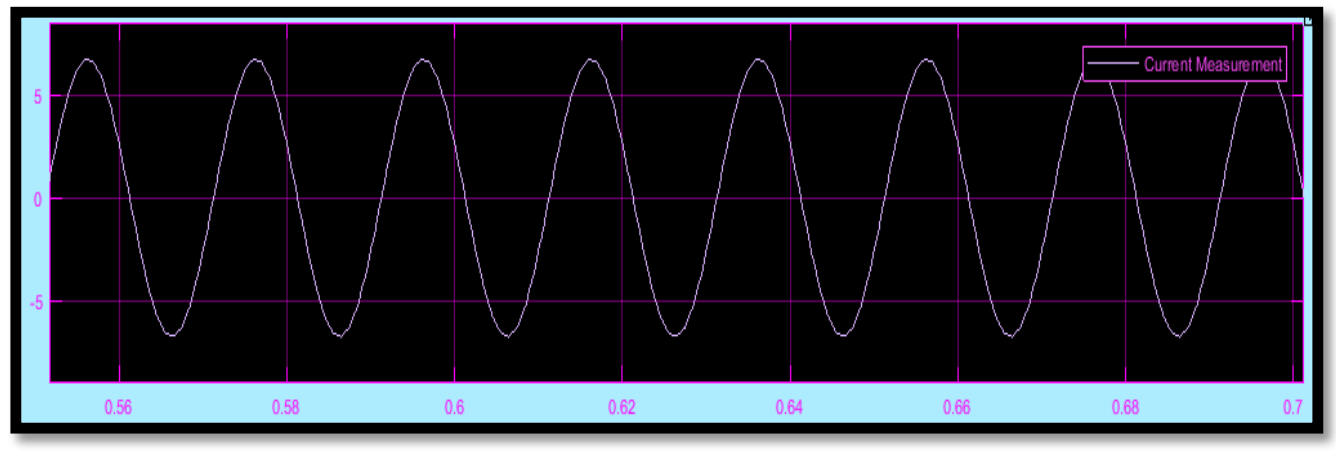

Figure 9. Output current waveform 


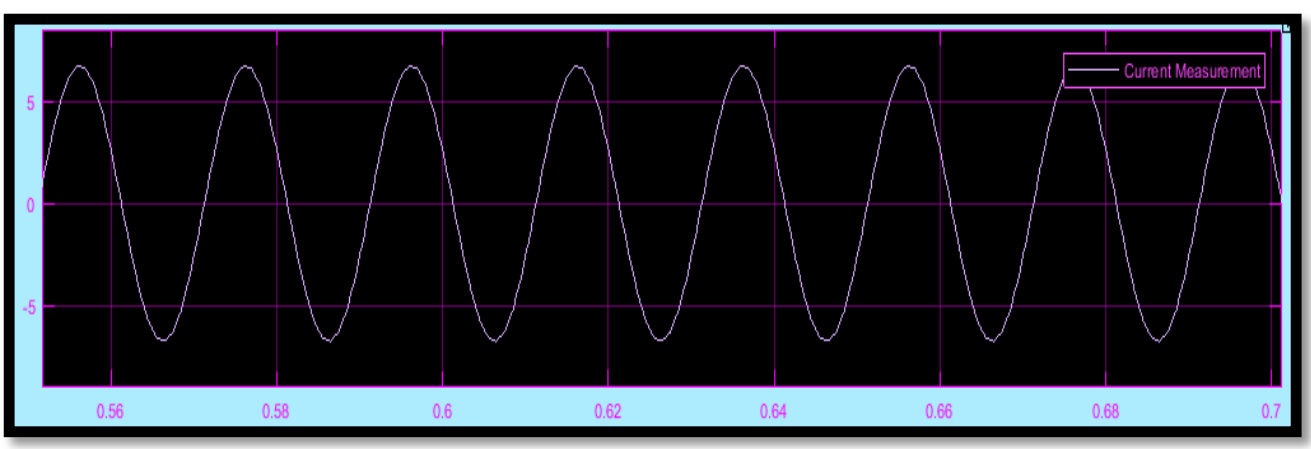

Figure 10. Output voltage waveform

\subsubsection{Case 2: Bipolar Switching Scheme}

For bipolar, the output rms initiate that the rms voltage is $305.3 \mathrm{~V}$ and the rms current is $6.107 \mathrm{~A}$ respectively. The filtered output current and voltage produced by bipolar switching scheme acquired from simulation are demonstrated in Figure 11 and 12.

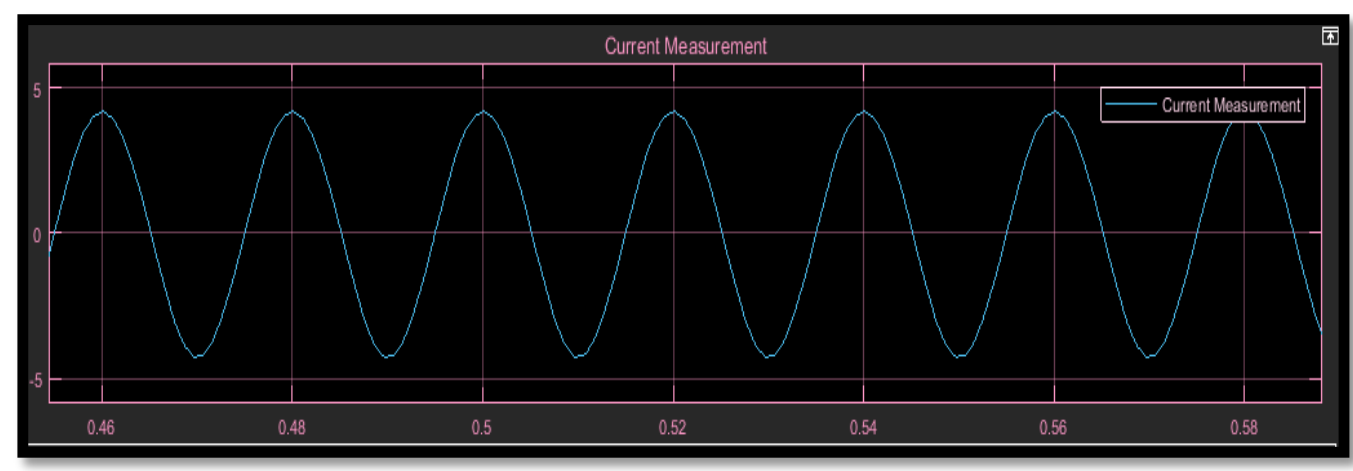

Figure 11. Output current waveform

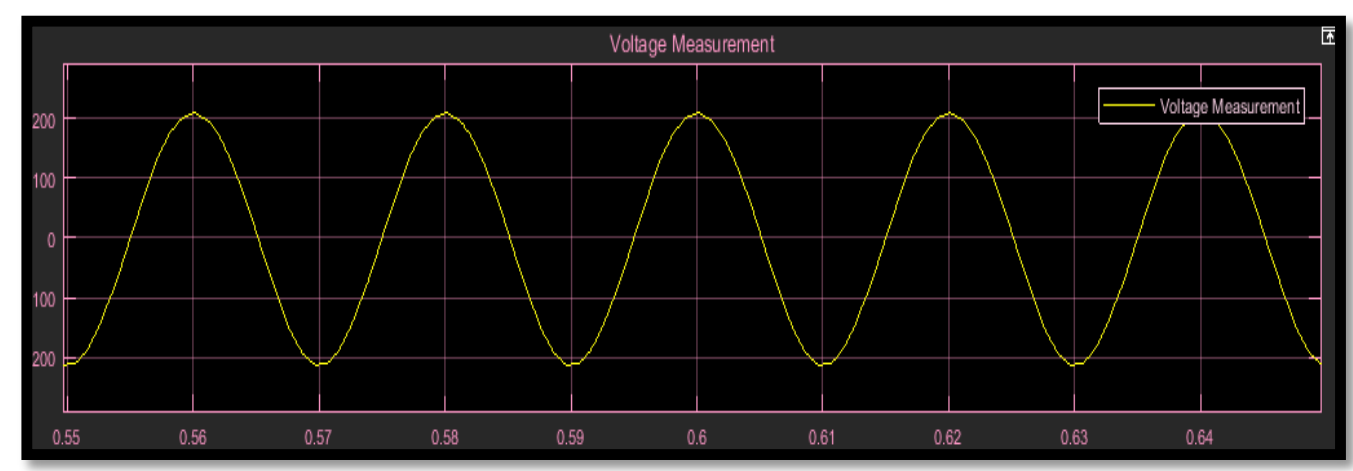

Figure 12. Output voltage waveform

Based on the result acquired from both schemes, it can be observed that the unipolar switching scheme produced more output current and voltage compared to the bipolar switching scheme.

\subsection{Analysis of Total Harmonic Distortion using FFT}

The THD analysis is performed in order to determine the magnitude of harmonic component and phase of the input signal as a function of time. 


\subsubsection{Case 1: Unipolar Switching Scheme}

Based on the simulation, the THD of the output voltage and current in unipolar is determined as $1.91 \%$ while the fundamental current and voltage are $6.754 \mathrm{~A}$ and $337.7 \mathrm{~V}$ respectively. Figure 13-16 show the signal magnitude and the frequency spectrum of output current and voltage for unipolar switching scheme in FFT analysis.

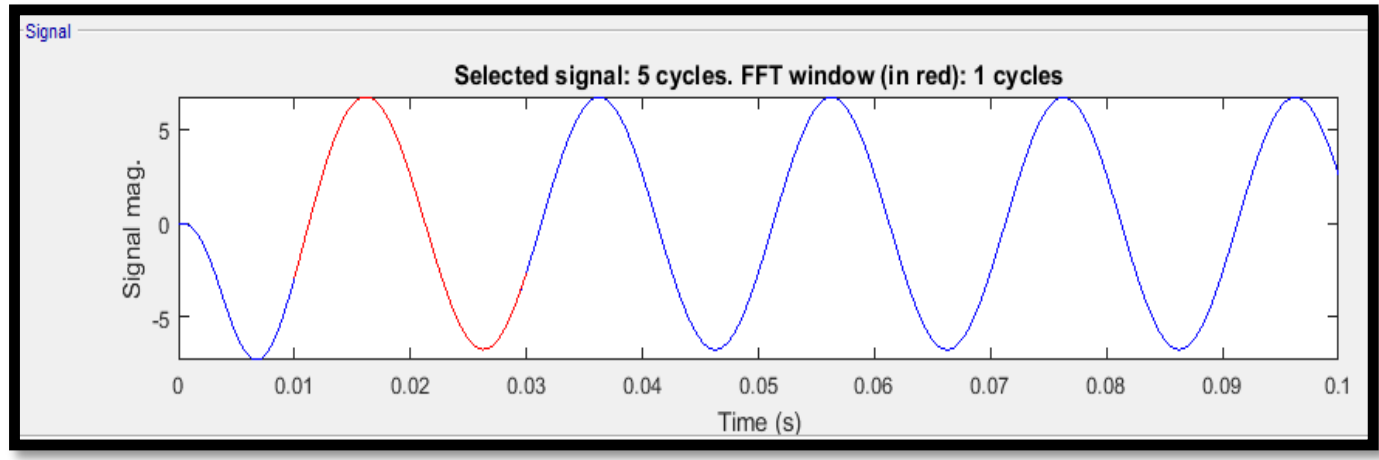

Figure 13. Signal magnitude of output current

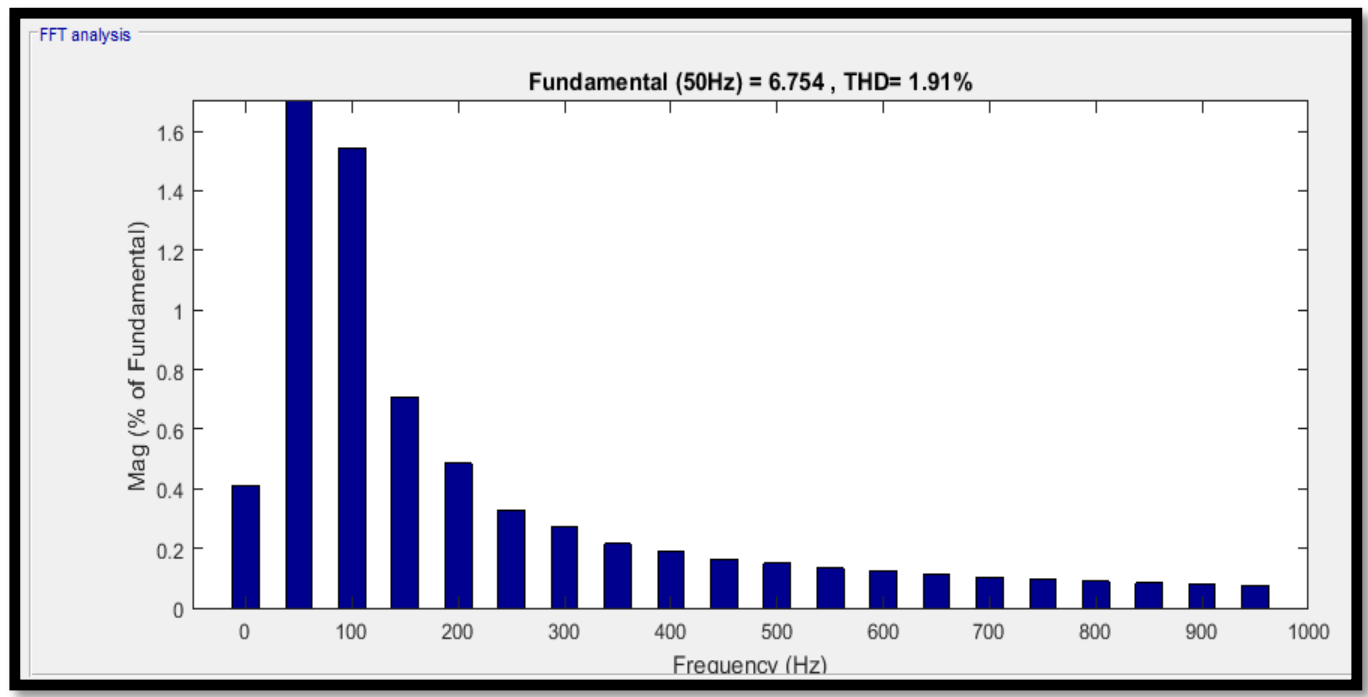

Figure 14. Frequency spectrum of output current

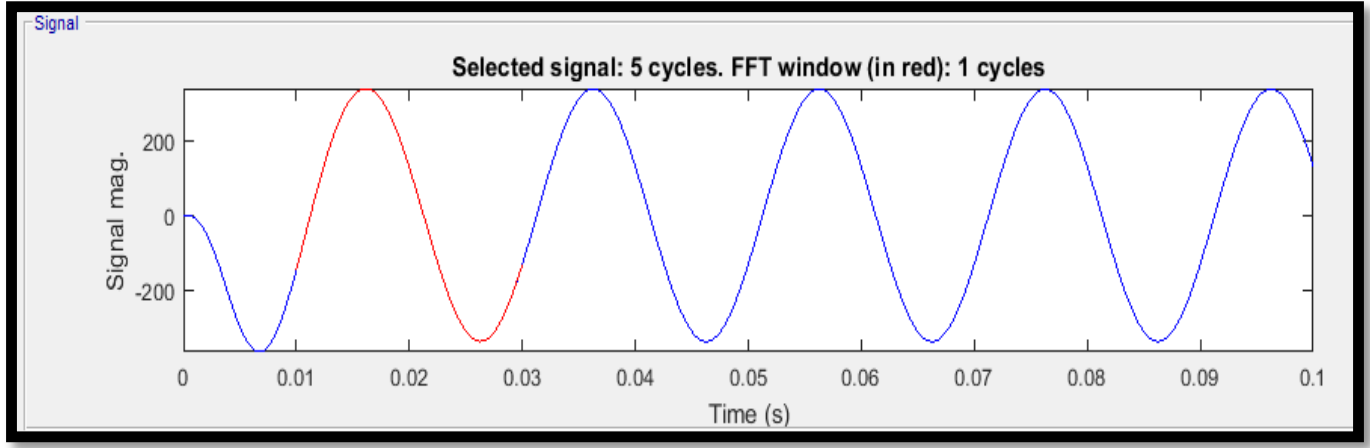

Figure 15. Signal magnitude of output voltage 


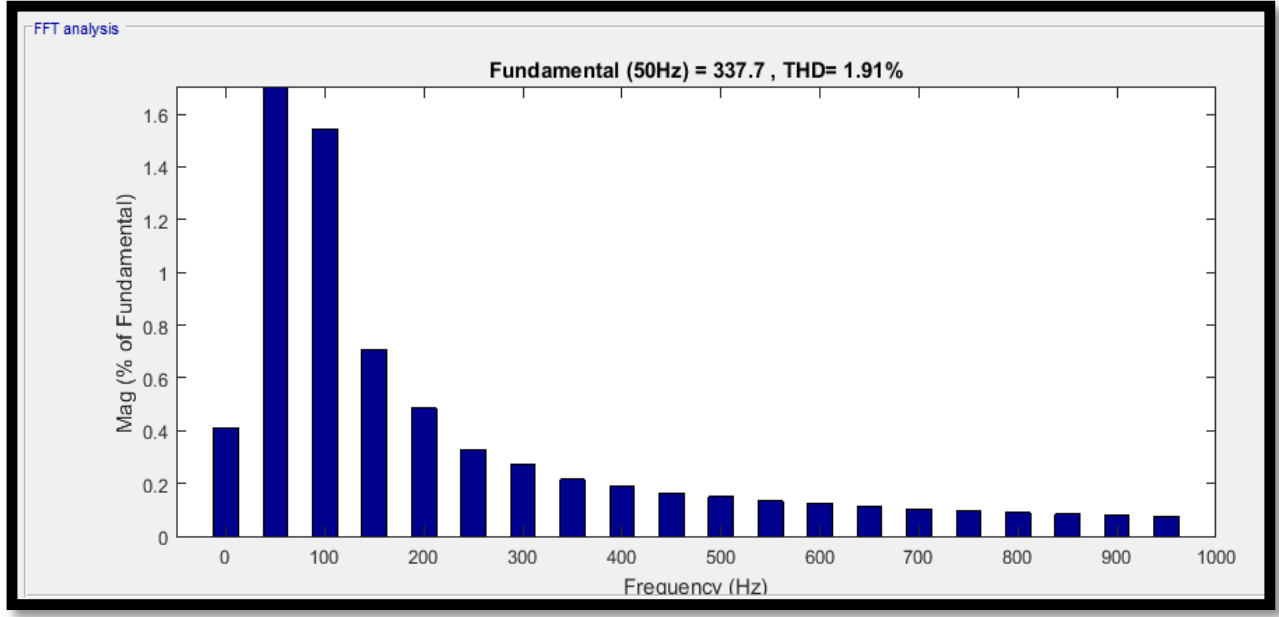

Figure 16. Frequency spectrum of output voltage

\subsubsection{Case 2: Bipolar Switching Scheme}

As for the simulation of this scheme, the THD of the output voltage and current in bipolar is determined as $2.50 \%$ while the fundamental current and voltage are $4.68 \mathrm{~A}$ and $337.7 \mathrm{~V}$ respectively. Figures 17 and 18 show the signal magnitude and the frequency spectrum of output current for bipolar scheme in FFT analysis.

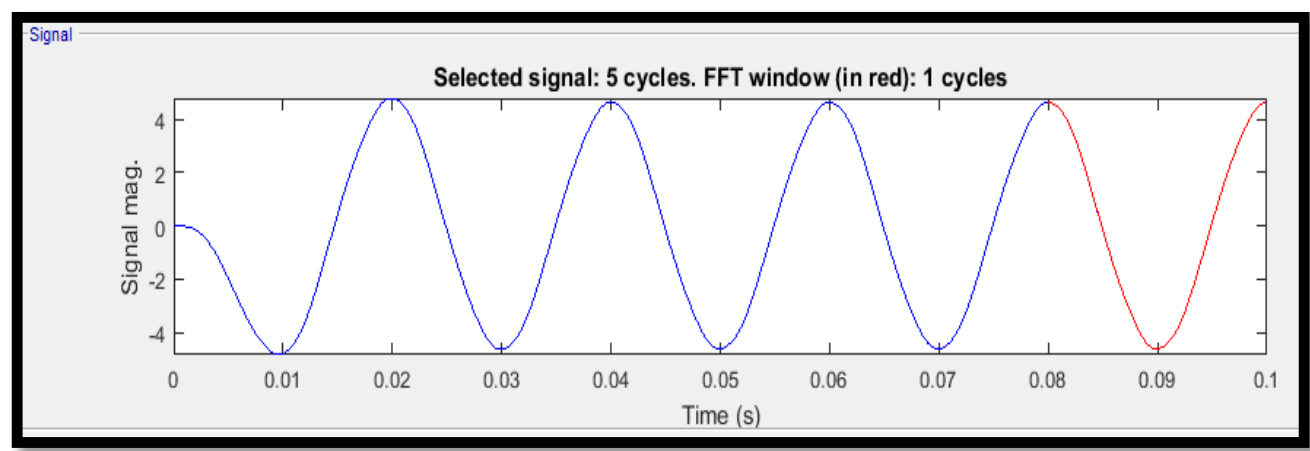

Figure 17. The signal magnitude of the current in FFT analysis

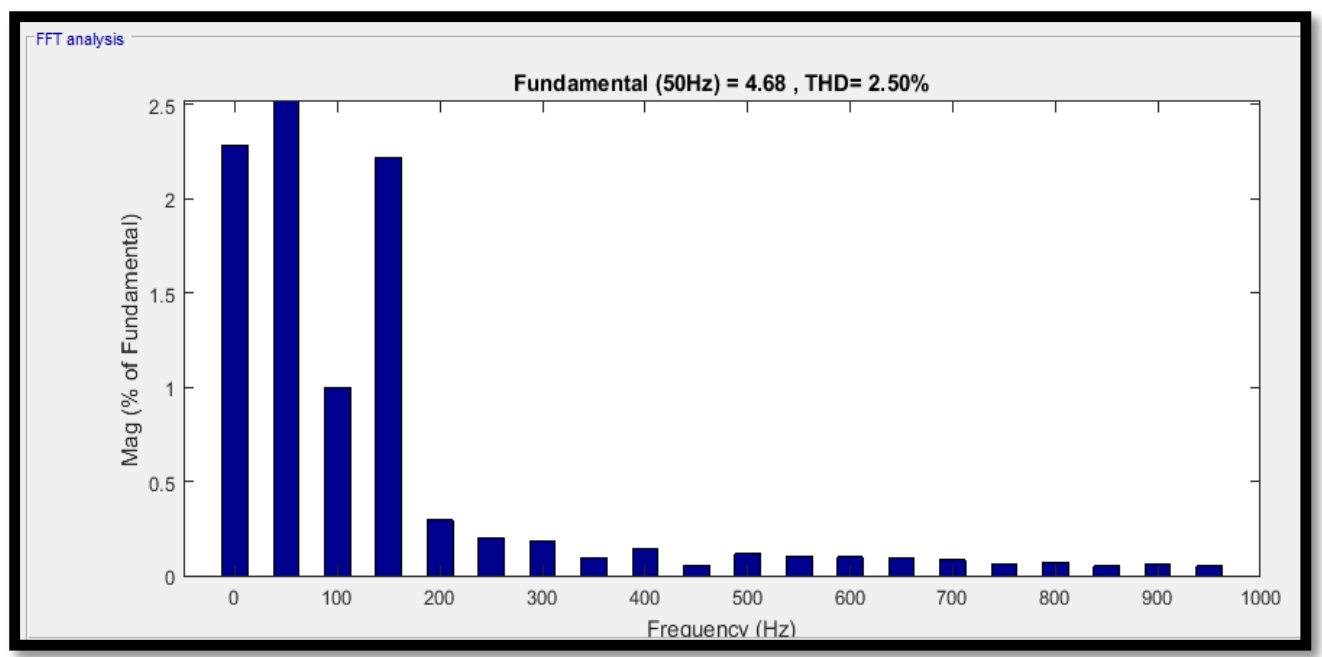

Figure 18. The frequency spectrum of the output current 
Figures 19 and 20 show the signal magnitude and the frequency spectrum of output voltage for bipolar scheme in FFT analysis.

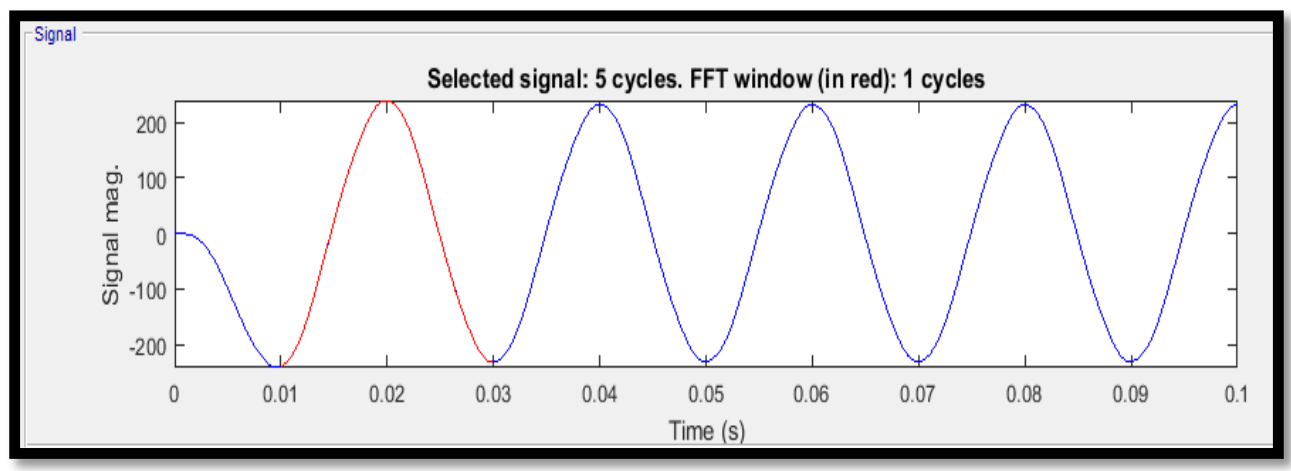

Figure 19. The signal magnitude of voltage in FFT analysis

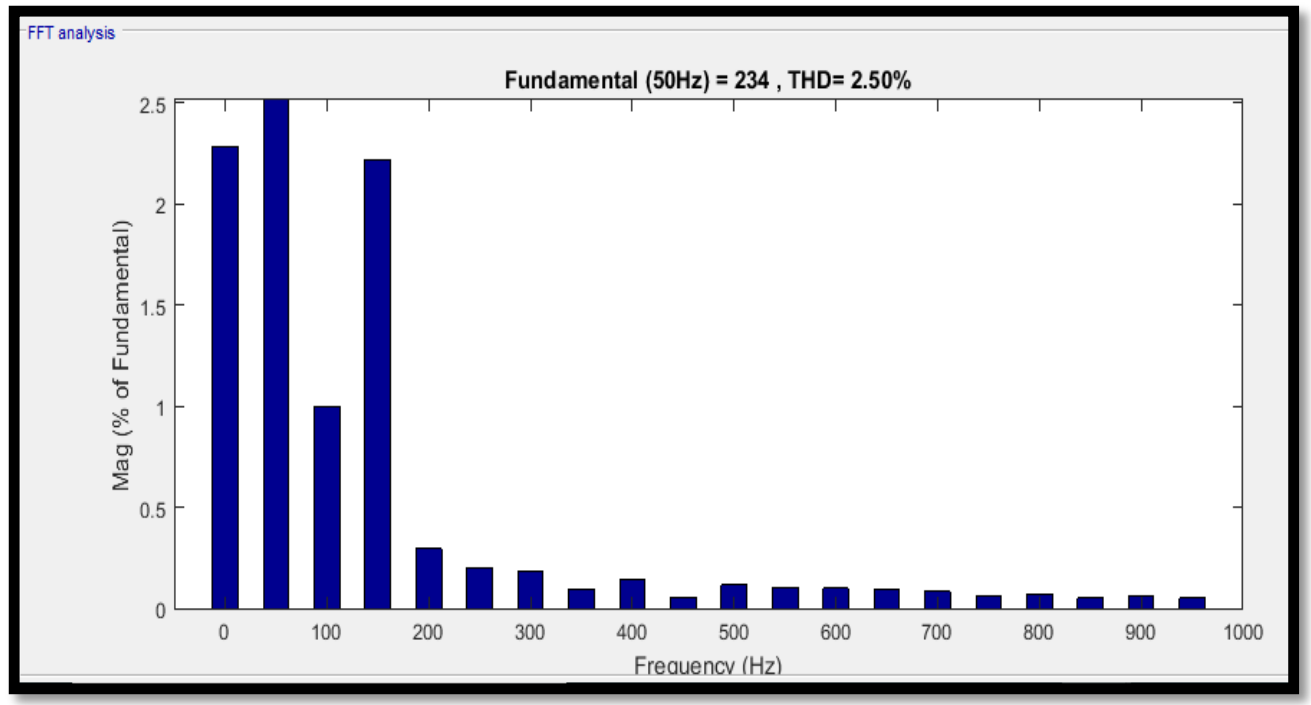

Figure 20. Frequency spectrum of the output voltage

Based on the result acquired from both scheme, it can be observed that the bipolar switching scheme produced more harmonic distortion compared to the unipolar switching scheme. It can be concluded that the unipolar switching scheme offered better performance in term of efficiency and lower THD as compared to bipolar switching scheme.

\section{RESULTS DISCUSSION}

The use of renewable energy still has many limitations and still face many technical difficulties. The application of power electronics in renewable energy generation also lack of complete and efficient procedure that tackles the existing problems $[19,25]$. Due to the fluctuating nature of renewable energy sources, there are many issues associated with that. For instance, the harmonics presence which has a severe impact on the overall electrical power system. In this study, a single phase standalone inverter for photovoltaic application has been designed. The main features of the designed inverter are that; it has been controlled using two different schemes. Unipolar and bipolar switching schemes with a filter circuit to reduce the presence of harmonics according to system standards. The proposed design has produced promising results in term of response as well as harmonics reduction. The obtained results have been compared to those published in [26], the current study produced very good results with minimal use of power electronics which reflects on the overall cost. In term of technicality, the harmonics level has been reduced to be within the standard $(5 \%)$. 


\section{CONCLUSION}

This work presented a single phase standalone inverter controlled with sinusoidal pulse-widthmodulation (SPWM) and low pass filter. It is connected between the inverter and the utility grid to reduce the harmonics presence due to intermittent nature of the renewable energy sources. The research carried out two case studies, which are: the first case study is related to unipolar switching scheme while the second case study is lying on bipolar switching scheme. To sum it up, both schemes have been studied in depth and both results are being compared. The design of the PV single phase inverter system and the development of SPWM switching scheme were accomplished. The implementation of filter circuit to eliminate the harmonic distortion in the system also achieved. Output voltage and output current for both schemes were analyzed. Next, the THD analysis for both schemes have been performed by using FFT analysis. Based on both results acquired from unipolar and bipolar switching scheme, the unipolar switching scheme gives better performance than bipolar switching scheme. The reason is, unipolar switching scheme produced more output current and output voltage. By analyzing the simulation work, the unipolar switching scheme produced a better sinusoidal output waveform and less harmonic distortion compared to the bipolar switching scheme. Although bipolar switching scheme have low power quality compared to unipolar scheme, its complex of control is simple compared to unipolar scheme. The limitations in this research are the parasitic resistance of LC filter is neglected and the input voltage from PV system is assumed to be constant without any ripple. As for the single phase inverter, unipolar and bipolar switching scheme, further research can be accomplished such as the soft switching inverters, single-phase UPS and single-phase induction motor drives. As part of future work, the analysis of state space and FFT algorithm can be perform.

\section{Acknowledgement}

The authors would like to express their gratitude to Universiti Kuala Lumpur for supporting and funding this research under grant No. str18005.

\section{REFERENCES}

[1] K Prasada Rao, Sukhdeo Sao, JBV Subrahmanyam, Design and Analysis of a Novel Multilevel Inverter Topology Suitable for Renewable Energy Sources Interfacing to AC Grid for High Power Application. International Journal of Scientific and Research Publications, Volume 3, Issue 5, May 2013

[2] Asim H. Syed, M. A. Abido, New Robust Controller Design for Voltage Source Inverters in Microgrids, 2014 22nd Mediterranean Conference on Control and Automation (MED)

[3] Jian Liu, Wenxi Yao, Zhengyu Lu, Xiaoyi Xu, Design and Implementation of DSP based High- Frequency SPWM Generator, IEEE 8th International Power Electronics and Motion Control Conference (IPEMC-ECCE Asia), 2016

[4] Olawale I. Adekol, Ali M. Almaktoof and A. K. Raji, Design of a Smart Inverter System for Photovoltaic Systems Application. 2016

[5] L. Bo and X. Guo-Chun, Comparison of performance between bipolar and unipolar double-frequency sinusoidal pulse width modulation in a digitally controlled H-bridge inverter system, Chinese Physics B, vol. 22, 2013.

[6] Deepa Sankar. Cascaded H-Bridge Multilevel Inverter Topologies for PV Application: A Comparison. International Conference on Circuit, Power and Computing Technologies (ICCPCT). 2016.

[7] Krismadinata; Nasrudin Abd. Rahim; Hew Wooi Ping; Jeyraj Selvaraj. Photovoltaic Module Modeling using Simulink/Matlab. The 3rd International Conference on Sustainable Future for Human Security. 2012.

[8] Leon M. Tolbert; Fang Z. Peng. Multilevel PWM Methods at Low Modulation Indices. Georgia Institute of Technology.

[9] CH. Ashlesha; A. Mounika; B. Aparna; N. Sharada, Design of Single Phase H-Bridge MultiLevel Inverter using Microcontroller ATMEL 89C51. 2008-2012.

[10] Rathore S.; Kirar M. K.; S.K Bhardwaj, Simulation of Cascaded H-Bridge Multilevel Inverter using PD, POD, APOD Techniques. Electrical \& Computer Engineering: An international Joinal (ECIJ) Volume 4, No. 3. September 2015.

[11] L. Bowtell and T. Ahfock, "Comparison between unipolar and bipolar single phase grid connected inverters for PV applications, " IEEE in Power Engineering Conference (AUPEC 2007) Australasia Universities, pp. 1-5, 2007.

[12] Sujanarko, B., Simulation Development of Carrier based Pulse Width. International Journal of Computer Applications. Department of Electrical Engineering, University of Jember, 2014.

[13] Nordvall, A., Multilevel Inverter Topology Survey. Master of Science Thesis in Electric Power Engineering. Division of Electric Power Engineering, Department of Energy and Environment. Göteborg, Sweden: Chalmers University Of Technology, 2011.

[14] Gerson E. M.; Lactec; Eduardo P. R. Total Harmonic Distortion Calculation by Filtering for Power Quality Monitoring.

[15] Hart, D. W., Power Electronics. Pg 339. New York: McGraw-Hill. 2011.

[16] Rajesh Ingale. Harmonic Analysis Using FFT and STFT. International Journal of Signal Processing and Pattern Recognition, Vol. 7, No. 4. 2014. 
[17] Hanim H.; Azilah S.; Mohd. Das Risin; Maizan Muhamad. Fast Fourier Transform Analysis on Harmonic Content for SPWM Design and Implementation Based on New Modulation Approach. Proceedings of the 9th WSEAS International Conference on Microelectronics, Nanoelectronicss, Optoelectronics.

[18] T.B. Mohite Patil, S.R. Sawant, R.H. Chile and T.T. Mohite Patil, Mathematical and Simulation Model of an SPWM Inverter. International Journal of Electronic and Electrical Engineering Volume 4, Number 1 (2011), pp.23-32

[19] I Alhamrouni, M Salem, A. Jusoh, NRN Idris, B Ismail, FM Albatsh, "Comparison of Two and Four Switches Inverter Feeding Series Resonant Converter”, 2017 IEEE Conference on Energy Conversion (CENCON), 2017.

[20] M Salem, A. Jusoh, NRN Idris, I Alhamrouni, "Comparison of LCL Resonant Converter with Fixed Frequency, and Variable Frequency Controllers” 2017 IEEE Conference on Energy Conversion (CENCON).

[21] Ibrahim Alhamrouni, Wan Ismail Hanis, Mohamed Salem, Fadi M. Albatsh, and Bazilah Ismail "Application of DC-DC Converter for E.V Battery Charger Using PWM Technique and Hybrid Resonant", 2016 IEEE 6th International Conference on Power and Energy (PECON 2016).

[22] Mohamed Salem, Awang Jusoh, N. Rumzi N. Idris, Himadry Shekhar and Ibrahim Alhamrouni, "Resonant power converters with respect to passive storage (LC) elements and control techniques-An overview" June 2018, Renewable and Sustainable Energy Reviews 91(August 2018).

[23] M Salem, A Jusoh, NRN Idris, I Alhamrouni. "Extension of Zero Voltage Switching range for series resonant converter" Energy Conversion (CENCON), 2015 IEEE Conference on, 171-175

[24] I Alhamrouni, MK Rahmat, FA Ismail, M Salem, A Jusoh, T Sutikno. "Design and development of SEPIC DC-DC boost converter for photovoltaic application” Int J Pow Elec \& Dri Syst ISSN 2088 (8694), 8694

[25] M Salem, A Jusoh, NRN Idris, I Alhamrouni "A Review of an Inductive Power Transfer System for EV Battery Charger”, European Journal of Scientific Research 107 (1), 42-56.

[26] Cathrine E. S. Feloups; Ahmed I. M. Ali ; Essam E. M. Mohamed. "Design of single-phase sevenlevel inverter with reduced number of switching devices for PV applications" 2017 Nineteenth International Middle East Power Systems Conference (MEPCON), Page s: 817 - 822. 